\title{
Harmony Search-Fractional order based Controller for Proton Exchange Membrane Fuel Cell powered Vehicles
}

\author{
Vinu RAMADHAS ${ }^{1 *}$, Varghese PAUL ${ }^{2}$, Kishore RAJENDIRAN ${ }^{3}$ \\ ${ }^{1}$ Anna University, Chennai, Tamil Nadu, India \\ vinur81@gmail.com (*Corresponding author) \\ ${ }^{2}$ Toc H Institute of Science and Technology, Cochin, Kerala, India \\ vp.itcusat@gmail.com \\ ${ }^{3}$ SSN College of Engineering, Chennai, Tamilnadu, India \\ kishorer@ssn.edu.in
}

\begin{abstract}
Fuel cell powered vehicles are comparatively more efficient than conventional vehicles which utilise fossil fuel as a main fuel source for energy conversion. This paper discusses Harmony Search optimized Fractional Order Proportional Integral Derivative (HS-FPID) controller which is used to regulate the speed of the Proton Exchange Membrane Fuel Cell (PEMFC) powered vehicle. The robust and the swift response of the HS-FPID controller makes it superior to other existing controllers and hence it is also utilized to control the DC Motor speed of PEMFC powered vehicles. The robustness and the swiftness of the HS-FPID controller is established using MATLAB Simulink.
\end{abstract}

Keywords: Proton Exchange Membrane Fuel cell, Harmony Search Optimization, Fractional Order PID Controller.

\section{Introduction}

Energy is the prime factor that plays an important part in establishing a country's economy as well as its industrial growth. The demand for alternative energy is rising worldwide due to the drastic decrease in fossil fuel reserves. Fossil fuels are the major sources of energy employed widely in transportation and they lead to an increase in hazardous green house gas emissions. Therefore an increase in the employment of renewable energy sources and associated technologies is necessary to transform the world to a carbon free and safe environment (Raissi \& Banerjee,1997). Fuel cell technologies are trendsetters in the field of renewable energy as they are believed to be the key solutions for the $21^{\text {st }}$ century since they are capable of alleviating the environmental distress and dealing with the security concerns in the context of energy supply. Fuel cells can facilitate hydrogen economy and they can be used in transportation, power distribution, heat generation and energy storage systems (Fuel Cell Hand Book, 2007).

Since fuel cells are an alternative in energy conversion, many research works are carried out by scientists and technology developers to promote advancements in fuel cell technology. Out of the various types of fuel cells, PEM fuel cells are considered as the most significant revolutionary energy converters due to its highenergy density at low operating temperatures, quick start-up and nil emission and suits applicable in automotive, stationary as well as portable applications. Though fuel cell has many advantages there are some primary issues related to the reliability, performance and cost which has to be rectified, to replace the place of conventional energy converters. Some of the primary issues that have to be overcome are to maintain optimal fuel and air flow rate whenever load changes, thermal, pressure and humidity management (Sopian, Wan $\&$ Daud, 2006). A stable operation of PEMFC requires effective control over the voltage or power under varying operating environments (Nandikesan et. al, 2012).

The nonlinear time-varying characteristics of PEMFC system along with the rigid operating conditions poses mammoth difficulties and challenges in PEMFC control (Ali \& Abhudhahir, 2011). Hence a reliable controller is required to satisfy the PEMFC system objectives. Due to the limitations of tracking performance by conventional controllers, a Harmony search optimized Fractional Order PID Controller is proposed to improve the tracking performance. Fractional order controller works on real time values provides extra two degrees of freedom in tuning and Harmony search Algorithm helps to tune the controller parameters quickly with minimum errors. Finally, the validation of the HSFPID controller was done by controlling the speed of a DC Motor of fuel cell powered vehicles under static as well as dynamic load conditions. The control algorithm employed is Harmony search Optimized Fractional Order PID Controller which settles quickly and is prone to minimal system errors as compared with other controllers (Vinu \& Paul, 2018). 
In order to analyze the performance and characteristics of PEM fuel cell systems, a thorough and systematic analysis on the facts of the various parameters in a fuel cell is essential (William et. al, 2008). It is difficult to understand the phenomena in the fuel cell as the relationship between the parameters are highly nonlinear (Salmasi, 2007). Hence the assistance of the simulations technique is availed of in order to understand and analyze the PEM fuel cell systems. Simulations make use of mathematical models which play a key role in fuel cell development and in demonstrating the actual behavior of the fuel cell. The characteristics of a Proton Exchange Membrane Fuel Cell in this paper are illustrated by using the State space Model of the PEM fuel cell (Puranik, Keyhani \& Khorrami, 2010).

The paper is organized as follows. In Section 2 the mathematical model of PEMFC is presented. In Section 3 the mathematical model of DC Motor is described. The Harmony Search-Fractional Order based Controller design is discussed in detail in Section 4. In Section 5 the simulation of the Controller under static and dynamic load conditions are explained. Finally the conclusions of the work are presented in Section 6.

\section{Mathematical Model of PEMFC}

Mathematical Modeling is a significant means which facilitates learning in detail about the static and dynamic behavior of fuel cells. It also contributes to the fuel cell components` design optimization and directs the evaluation of various control strategies. A nonlinear control-oriented Model is required to do the performance analysis as the correlation between the parameters of PEM fuel cell is highly nonlinear.

In this paper, a $500 \mathrm{~W}$ non linear state space model based proton exchange membrane fuel cell is considered (Puranik, Keyhani \& Khorrami, 2010). This state space model considers the PEM fuel cell open circuit,mass thermodynamic balance, various voltage losses and double layer effects. This non linear state space model is considered for implementing PEMFC voltage tracking. The significant features of the PEMFC State Space Model are given as follows:

\subsection{Open Circuit Voltage}

The PEM fuel cell voltage is given by

$$
V_{\text {pemfc }}=V_{o c}-V_{\text {loss }}
$$

$\mathrm{V}_{\mathrm{oc}}$ is the voltage loss pertaining to PEM fuel cell open circuit voltage and $\mathrm{V}_{\text {loss }}$ is irreversible voltage loss in PEMFC. In a PEM fuel cell the open circuit output voltage is given as shown in (2)

$$
V_{o c}=n_{\text {stack }} E_{\text {cell }}^{\text {ref }}+\frac{n_{\text {stack }} R T}{2 F} \ln \left(\frac{P_{\mathrm{H}_{2}} P_{\mathrm{O}_{2}}}{P_{\mathrm{H}_{2} \mathrm{O}}}\right)
$$

where $\mathrm{n}_{\text {stack }}$ indicates the amount of PEM Fuel cell stacks, $E_{\text {cell }}^{\text {ref }}$ indicates the reference cell potential in normal operating conditions $(\mathrm{V})$, $\mathrm{T}$ represents the Temperature of $\operatorname{stack}(\mathrm{K}), \mathrm{F}$ corresponds to Faraday's Constant $(\mathrm{C} / \mathrm{mol}), \mathrm{R}$ indicates the Universal gas constant $[\mathrm{J} /(\mathrm{molK})]$, $P_{H_{2}}$ represents the Hydrogen partial pressure (atm), $P_{0_{2}}$ and $P_{\mathrm{H}_{2} \mathrm{O}}$ indicate the Oxygen and Water partial pressures (atm) (Puranik, Keyhani \& Khorrami, 2010) respectively.

\subsection{Irreversible Voltage Losses}

The PEM fuel cell is characterised by following three types of voltage losses: Activation loss, Ohmic loss and Concentration loss (Puranik, Keyhani $\&$ Khorrami, 2010). The correlation between the irreversible voltage loss is given by (3)

$V_{\text {loss }}=V_{\text {activ }}+V_{\text {ohm }}+V_{\text {con }}$

where $\mathrm{V}_{\text {activ }}$ is voltage loss due to the sluggish kinetic nature of electrons and it is known as activation loss which is given by

$V_{\text {activ }}=\left(\frac{R T}{2 F}\right) \ln \left(\frac{I}{I_{d}}\right)$

$V_{\text {ohm }}$ is the voltage loss due to the motion of protons via the electrolyte and the electrons all the way through the electronic resistance known as Ohmic loss and it is given by

$V_{\text {ohm }}=V_{A}^{O}+V_{C}^{O}+V_{M}^{O}$

$V_{A}^{O}$ is the voltage developed across anode (volts), $V_{C}^{O}$ is the voltage developed across cathode (volts) and $V_{M}^{O}$ indicates the voltage developed across the proton exchange membrane (volts).

$\mathrm{V}_{\text {con }}$ indicates the voltage loss obtained because of the difference in the concentration of reactants at the outer shell of electrodes. It is known as Concentration loss and it is represented as

$V_{c o n}=\frac{R T}{e F} \ln \left(1-\frac{I}{I_{L}}\right)$

where e represents the amount of electrons and $I_{L}$ is the Limiting current(A). 


\subsection{Humidification}

The PEMFC consists of a thin membrane which has to be humidified in order to allow the protons $\left(\mathrm{H}^{+}\right.$ions) thereby to increase the PEM fuel cell efficiency. The Ohmic resistance of thin membrane increases as the humidity in the membrane decreases. Therefore, the inputs to the PEM fuel cell like hydrogen and oxygen/air are allowed to pass through a humidification system to get humidified before entering the electrodes (Puranik, Keyhani \& Khorrami, 2010).

\subsection{Mass and Thermodynamic energy Balance}

The net mole flow rate of the reactants at cathode/anode depends on the variation among the incoming flow rate of the reactants and their outgoing flow rates (Puranik, Keyhani \& Khorrami, 2010).

\subsection{Charge Double Layer}

In Proton Exchange Membrane Fuel cell the electrons flow through the external circuit to arrive at the cathode whereas the protons $\left(\mathrm{H}_{+}\right)$ ions flow through the thin membrane to arrive at the cathode. Thus oppositely charged layers are formed in the cathode which is known as double layer effect. This double layer can act as a capacitor and it can accumulate electrical charge (Puranik, Keyhani \&Khorrami, 2010).

\section{Mathematical Model of DC Motor}

DC Motors are employed in applications like Electric Vehicles, Electric railway tractions, Robotic Manipulators and in many industrial fields. In all the above-mentioned applications, control of the speed in the DC Motor is mandatory inorder to execute them. The Speed control in DC Motors is comparatively easier than in the case of AC Motors.

Figure 1 shows the equivalent circuit representation of DC Motor. $\mathrm{V}_{\mathrm{A}}$ represents the Armature coil voltage. Here the coil of the armature is represented as a series combination of Inductance $\left(\mathrm{L}_{\mathrm{A}}\right)$ with Resistance $\left(\mathrm{R}_{\mathrm{A}}\right)$ with the induced voltage $\left(\mathrm{V}_{\mathrm{C}}\right)$ opposing the source Voltage. The voltage induced is called Back emf $\left(V_{c}\right)$. Back emf (electromotive force) is created due to the coil rotation through the flux lines of permanent magnets. Figure 1 is the symbolic circuit representation of DC Motor. $\mathrm{V}_{\mathrm{A}}$ represents the Armature coil voltage. Here the coil of the armature is represented as a series combination of Inductance $\left(\mathrm{L}_{\mathrm{A}}\right)$ and resistance $\left(\mathrm{R}_{\mathrm{A}}\right)$ with the induced voltage $\left(\mathrm{V}_{\mathrm{C}}\right)$ opposing the source Voltage.

According to Kirchoff's Voltage Law(KVL) the summation of voltages in a closed loop is equal to zero. By applying KVL in the DC motor equivalent circuit given in Fig. 2,

$V_{A}-V_{L A}-V_{R A}-V_{C}=0$

The voltage across the resistor $\mathrm{R}_{\mathrm{A}}$ is given by Ohm's law as given below:

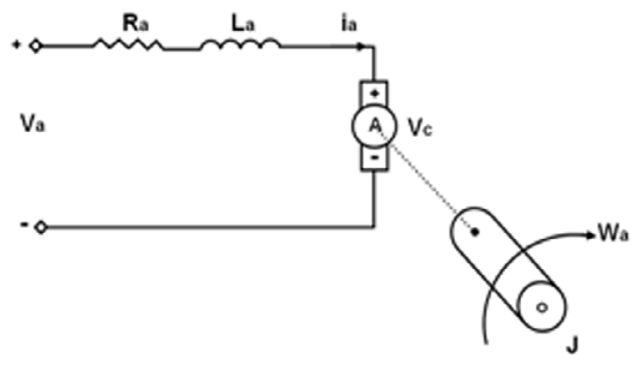

Figure 1. Model of DC Motor

$V_{R A}=I_{A} R_{A}$

where $\mathrm{I}_{\mathrm{A}}$ represents the armature current and $\mathrm{R}_{\mathrm{A}}$ represents the armature resistance. The voltage developed across the inductor $\mathrm{V}_{\mathrm{LA}}$ is directly proportional to the variation of current along the coil with respect to time and it is represented as:

$V_{L A}=L_{A} \frac{d}{d t}\left(I_{A}\right)$

where $\mathrm{L}_{\mathrm{A}}$ represents the amount of inductance in the armature coil.

Back emf is given as

$V_{C}=K_{V} \omega_{A}$

where $\mathrm{K}_{\mathrm{v}}$ is given as velocity constant and it depends upon the flux density of the permanent magnets, the reluctance of the iron core in the armature, and the number of turns in the armature winding. $\omega_{\mathrm{A}}$ is the armature rotational velocity.

$V_{A}-L_{A} \frac{d}{d t}\left(I_{A}\right)-I_{A} R_{A}-K_{V} \omega_{A}=0$

\subsection{Mechanical Characteristics}

To achieve the energy equilibrium in the system, the summation of the torques in the motor should be equivalent to zero. Summation of torque is represented as

$T_{E}-T_{W}-T_{V}-T_{L}=0$ 
where $T_{E}$ represents the electromagnetic torque, $\mathrm{T}_{\mathrm{W}}$ represents the torque developed by rotational acceleration of rotor, $\mathrm{T}_{\mathrm{V}}$ represents the torque developed due to rotor velocity and $T_{L}$ represents the torque of mechanical load. The electromagnetic torque $\mathrm{T}_{\mathrm{E}}$ is proportional to the current along the armature winding and is represented as

$T_{E}=K_{T} I_{A}$

where $\mathrm{K}_{\mathrm{T}}$ represents the torque constant. The torque developed due to rotational acceleration of the rotor is represented as:

$$
T_{W}=J \frac{d}{d t}\left(\omega_{A}\right)
$$

where $\mathrm{J}$ represents the moment of inertia of the load. The torque associated with the velocity is written as

$T_{V}=B \omega_{A}$

By substituting the above values (13), (14), (15) in equation (16), equation (12) becomes

$$
K_{T} I_{A}-J \frac{d}{d t}\left(\omega_{A}\right)-B \omega_{A}-T_{L}=0
$$

The Armature Current and the Angular Velocity based on equations (11), (16) can be represented as

$$
\begin{aligned}
& \frac{d}{d t}\left(I_{A}\right)=-\frac{R_{A}}{L_{A}} I_{A}-\frac{K_{V}}{L_{A}} \omega_{A}+\frac{V_{A}}{L_{A}} \\
& \frac{d}{d t}\left(\omega_{A}\right)=\frac{K_{T}}{J} I_{A}-\frac{B}{J} \omega_{A}+\frac{T_{L}}{J}
\end{aligned}
$$

The Laplace Transform of the above equations (17), (18) is given as follows:

$$
\begin{aligned}
& S I_{A}(S)-I_{A}(0)=-\frac{R_{A}}{L_{A}} I_{A}(S)-\frac{K_{V}}{L_{A}} \Omega_{A}(S)+\frac{V_{A}}{L_{A}}(19) \\
& S \Omega_{A}(S)-\omega_{A}(0)=-\frac{K_{T}}{J} I_{A}(S)-\frac{B}{J} \Omega_{A}(S)-\frac{T_{L}}{J}(S)
\end{aligned}
$$

Considering the initial conditions as zero ,the equations (19) and (20) above become

$$
\begin{aligned}
& I_{A}(S)=\frac{-K_{V} \Omega_{A}(S)+V_{A}(S)}{L_{A}(S)+R_{A}} \\
& \Omega_{A}(S)=\frac{-K_{T} I_{A}(S)-T_{L}(S)}{J S+B}
\end{aligned}
$$

Figure 2 represents the block diagram of DC Motor model.

\section{HS-FPID Controller Design}

\subsection{Fractional Order PID Controller}

Fractional Calculus is a mathematical advancement which deals with fractional or real-time values (Chen, Petras \& Xue, 2009). The traditional PID Controller performance can be improved by considering Fractional/real time values.

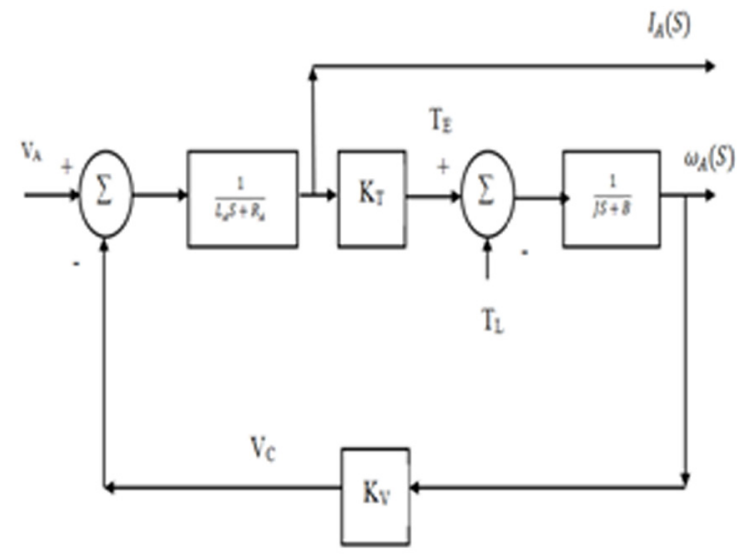

Figure 2. Block Diagram of DC Motor model

For a Fractional Order PID Controller, the transfer function is written as

$G_{F P I D}(S)=\frac{U(S)}{E(S)}=K_{P}+K_{I}(S)^{-\lambda}+K_{D}(S)^{\delta}$

where $\lambda$ and $\delta$ are the fractional values used in integral and differential order respectively (Zhang \& Li, 2011). The Control signal U(t) written in time domain is represented in (24)

$U(t)=K_{P} \varepsilon(t)+K_{I}\left(D_{t}\right)^{-\lambda} \varepsilon(t)+K_{D}\left(D_{t}\right)^{\delta} \varepsilon(t)$

where $\varepsilon(t)$ is the error signal (Maamar \& Rachid, 2014). The Fractional Order PID controller is also represented as $\mathrm{PI} \mathrm{I}^{\lambda} \mathrm{D}^{\delta}(\mathrm{Cao} \& \mathrm{Ca}, 2006)$. The real time values given by and $\delta$ provide additional degrees of freedom to Fractional Order PID Controllers (Barbosa \& Jesus, 2013). Hence, FPID Controllers achieve higher flexibility as compared with traditional PID Controllers (Singhal, Padhee \& Kaur, 2012).

\subsection{Design of FPID Controller}

The steps for the implementation of FPID Controller design are the following:

1. Determine the fitting parameters: Bandwidth, Filter Order n. 
2. Determine the controller parameters: $\mathrm{K}_{\mathrm{p}}, \mathrm{K}_{\mathrm{I}}$, $\mathrm{K}_{\mathrm{D}}$, Integral Order $\lambda$ and Differential Order $\delta$.

3. Calculate the transfer function of the FPID controller.

\subsection{Harmony Search Algorithm}

Harmony search (HS) Algorithm is an optimization technique used to identify the optimal solution or state of harmony (Bilbao et.al, 2014). In HS algorithm, each and every solution is termed as Harmony and it is represented by an $\mathrm{N}$-dimensional vector (Das et. al, 2011). In the initial state, the population of harmony vectors is randomly generated (Kassim, Sulaiman \& Mussirin, 2014). The harmony vectors are stored in a memory known as Harmony Memory (HM). Based on the Harmony Memory, new harmony is created by random re-initialization or by a pitch adjustment operation or by taking memory into consideration (Askarzadeh \& Rezazadeh, 2012). Finally, the HM is restructured by comparing the new candidate harmony with the worst harmony vector in the Harmony Memory. The worst harmony vector is reinstated by the new candidate vector in case the new value is better than the worst harmony vector in the HM. The above steps are repeated until a termination criterion is achieved.

\subsection{Design of HS Parameters}

Fitness function.

The harmony search algorithm is used to optimize the performance of the controller by minimizing the error between the reference input and output voltage. The minimization of error is the fitness function of the HS algorithm and it is represented as

$$
J=\operatorname{Min} \int_{0}^{\infty} \varepsilon(t) d t
$$

The controller performance is optimized by designing the FPID Controller parameters or control objectives such as $\mathrm{K}_{\mathrm{p}}, \mathrm{K}_{\mathrm{I}}, \mathrm{K}_{\mathrm{D}}, \lambda$ and $\delta$ (Vinu \& Paul, 2016).

\subsection{Selection of HS Parameters}

The Harmony Search Algorithm depends on parameters such as the Harmony-Memory Consideration Rate (HMCR), the distance Band Width (BW), Pitch Adjustment Rate (PAR) and the Number of Generations (NG) which gives the total number of iterations to optimize the performance (Bilbao et. al, 2014). HMCR is the harmony memory consideration probability of solution from the HM. This value helps to avoid being trapped in a local minima. PAR facilitates the production of a new value closer to existing solutions from HM. This parameter is also helpful for getting rid of local minima and also for achieving better solutions. The distance bandwidth parameter assists instabilization between local and global searches (Kassim, Sulaiman \& Mussirin, 2014).

The population or size of the Harmony Memory is 10 . The design parameters required for the harmony search algorithm are shown in Table 1.

Table 1. Design Parameters of Harmony Search Algorithm

\begin{tabular}{|l|c|}
\hline \multicolumn{1}{|c|}{ Parameters } & $\begin{array}{c}\text { Harmony } \\
\text { Search } \\
\text { Algorithm }\end{array}$ \\
\hline Harmony Memory Size (HMS) & 10 \\
\hline Bandwidth & 0.2 \\
\hline $\begin{array}{l}\text { Harmony Memory Consideration } \\
\text { Rate (HMCR) }\end{array}$ & 0.95 \\
\hline Pitch Adjustment Rate (PAR) & 0.6 \\
\hline
\end{tabular}

Table 2 shows the Optimized Controller Parameters after 50 iterations.

Table.2. Optimized HS-FPID Controller Parameters

\begin{tabular}{|c|c|c|c|c|c|c|c|c|c|c|}
\hline $\begin{array}{c}\text { Parameter } \\
(\mathbf{H M})\end{array}$ & $\mathbf{K}_{\mathrm{p}}$ & $\mathbf{K}_{\mathrm{I}}$ & $\lambda$ & $\mathbf{K}_{\mathbf{D}}$ & $\delta$ & $\mathbf{K}_{\mathrm{P}_{1}}$ & $\mathbf{K}_{\mathrm{I1}}$ & $\lambda_{1}$ & $\mathbf{K}_{\mathrm{D} 1}$ & $\delta_{1}$ \\
\hline Best & 2.081 & 38.3 & 0.793 & 1.54 & $\begin{array}{c}7.82 \mathrm{E}- \\
01\end{array}$ & 5.09 & 0.256 & 0.599 & 1.12 & 0.35 \\
\hline $\begin{array}{c}\text { Old } \\
\text { Harmony }\end{array}$ & 5.559 & 29.39 & 0.153 & 0.803 & $7 \mathrm{E}-01$ & 8.89 & 0.971 & 0.978 & $\begin{array}{c}1.34 \mathrm{E}- \\
01\end{array}$ & 0.311 \\
\hline $\begin{array}{c}\text { New } \\
\text { Harmony }\end{array}$ & 5.559 & 29.39 & 0.153 & 0.919 & $\begin{array}{c}8.94 \mathrm{E}- \\
01\end{array}$ & 8.76 & 0.945 & 0.978 & $\begin{array}{c}1.34 \mathrm{E}- \\
01\end{array}$ & 0.154 \\
\hline
\end{tabular}


With the help of Harmony Search Algorithm, FPID Controller parameters required to satisfy the fitness function are obtained as given in Table 2 .

The Harmony Memory solutions include the following Controller parameters $\left[\mathrm{K}_{\mathrm{p}}, \mathrm{K}_{\mathrm{I}}, \lambda, \mathrm{K}_{\mathrm{D}}, \delta\right]$. The range of the parameters is as follows:

Proportional Gain : $0 \leq \mathrm{K}_{\mathrm{p}} \leq 10$

Integral Gain : $0 \leq \mathrm{K}_{\mathrm{I}} \leq 100$

Differential Gain: $0 \leq \mathrm{K}_{\mathrm{D}} \leq 2$

Integral Order : $\lambda €[0,1]$

Differential Order: $\delta \in[0,1]$

\subsection{Closed loop Speed control for PEMFC- powered DC Motor}

The speed of the DC motor can be controlled either by varying its applied voltage or by changing its armature current in open loop control (Othman et. al, 2017). In open loop control the speed cannot be adjusted exactly to the mandatory value under any sudden load variations in the shaft (Monem, Azmy \& Mahmoud, 2014). Hence closed loop control is necessary for PEMFC-fed vehicles. The closed loop control helps in maintaining the required speed of motor shaft. This is achieved by providing a feedback from the motor shaft to the speed controller (Al-Othman et. al, 2016). Figure 3 shows the block diagram of the closed loop control of PEMFC fed vehicles.

In the system a sensor is employed in the feedback loop to sense the speed of motor shaft which is represented as $\omega_{\mathrm{m}}$. The measured speed of the motor shaft is compared with the reference speed represented as $\omega_{\text {ref }}$

The error in terms of speed is represented as

$\omega_{\text {error }}=\omega_{\text {ref }}-\omega_{m}$

The error value $\omega_{\text {error }}$ is given to the speed controller and a corresponding control voltage $\mathrm{V}_{\mathrm{c}}$ is generated. This control voltage $\mathrm{V}_{\mathrm{c}}$ is fed to the PEMFC to generate the output voltage $\mathrm{V}_{\text {o }}$ required to control the speed of DC Motor. This output voltage $\mathrm{V}_{\mathrm{o}}$ helps to control the speed of vehicle even under unanticipated load variations in the motor shaft. Whenever the speed of vehicle increases from a preset value due to a reduction in load, the error $\left(\omega_{\text {error }}\right)$ is also reduced. This reduced error value causes a reduction in the control voltage $\left(\mathrm{V}_{\mathrm{c}}\right)$. This leads to a reduction in the fuel flow rate of PEMFC eventually reducing the fuel cell output voltage $\left(\mathrm{V}_{\mathrm{o}}\right)$. The reduced PEMFC output voltage is given as the applied or armature voltage for the DC Motor. The reduction in the armature voltage compensates for the reduction in the load torque, and the speed of the DC motor can be resettled at a preset value. By contrast to this if the speed of electric vehicle decreases due to an increase in torque load the operation is reversed to compensate for the increase in the torque load and hence it maintains the desired speed at a preset value.

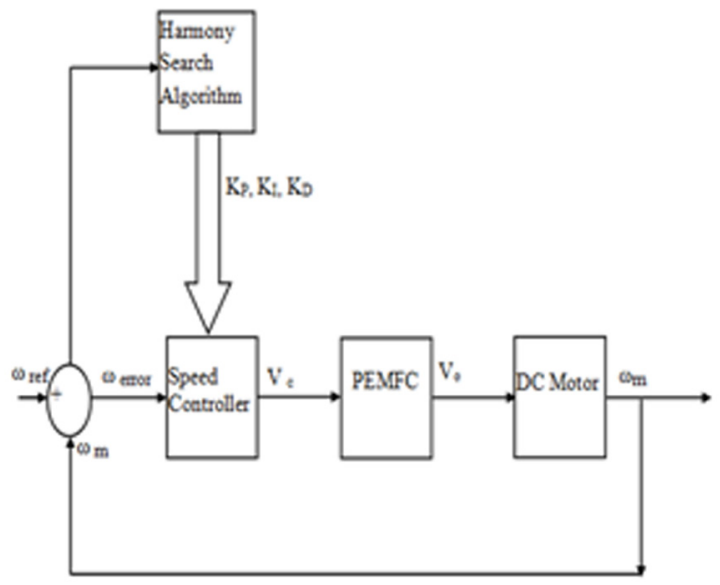

Figure 3. Closed loop Speed control for PEMFC powered DC Motor

\subsection{Implementation of Speed Control for PEMFC-powered DC Motor}

HS Optimized FPID Controller is considered to be the effective controller for a nonlinear system because of its better tracking capability, lower convergence time and fewer errors (Vinu, 2016, Vinu, 2018). Figures 4 and 5 show the effectiveness of HS-FPID Controller compared with traditional PID and Neural network Controllers. HS-FPID Controller tracks the reference speed very closely compared to others, under static as well as dynamic load conditions.

Figure 4 shows the HS-FPID Controller improves the performance by tracking the reference voltage closer by a value of 49.9998 whereas PID tracks the reference by 49.9912 and $\mathrm{NN}$ tracks by a value of 49.6780 .

The performance analysis of the controllers is estimated using the system error calculations. 


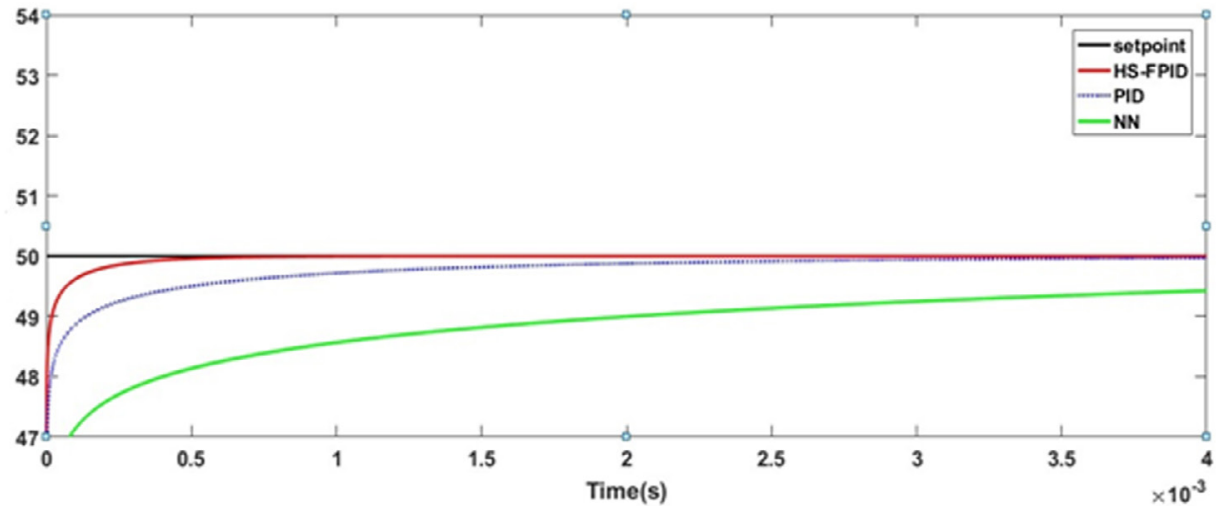

Figure 4. Comparison of HS-FPID Controller with PID and NN Controller under static condition

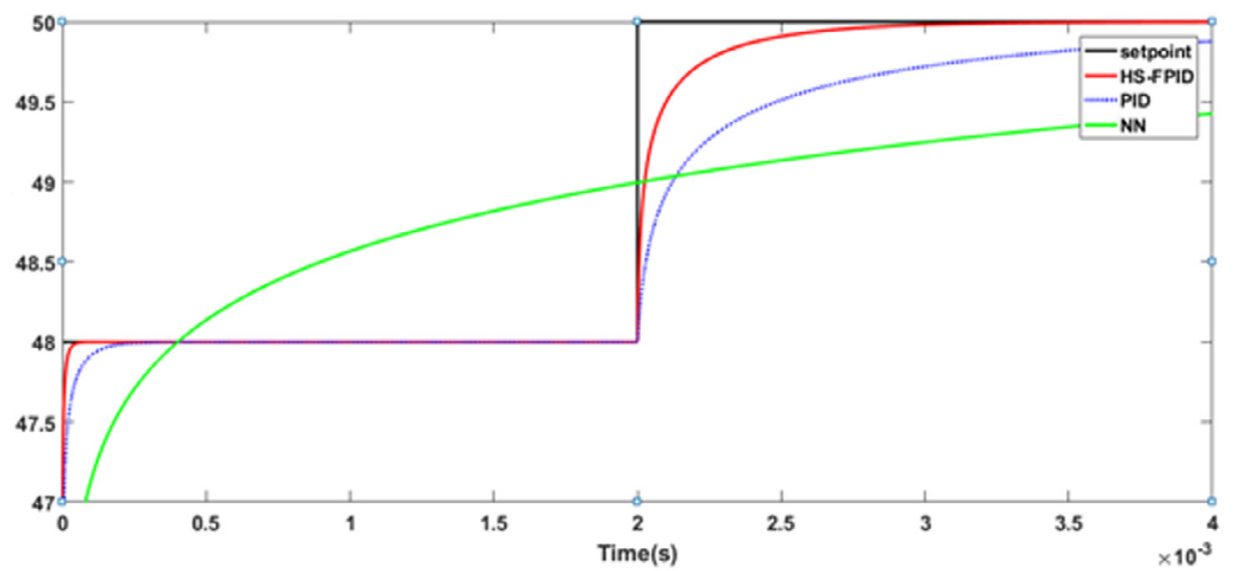

Figure 5. Comparison of HS-FPID Controller with PID and NN Controller under dynamic condition

The system errors are given as i) Integral Squared Error(ISE), (ii) Integral Absolute Error (IAE) and (iii) Integral Time-weighted Absolute Error (ITAE).

i) Integral Square Error: It integrates the square of the error with respect to time. It gives importance to large errors than smaller ones.

$$
I S E=\int e^{2}(t) d t
$$

ii) Integral Absolute Error: It integrates the absolute value of the error with respect to time and also it responds very slowly than ISE.

$$
I A E=\int|e(t)| d t
$$

iii) Integral Time-Weighted Absolute Error: It integrates the absolute value of the error multiplied by time and gives importance to prolonged errors.

$$
I T A E=\int t|e(t)| d t
$$

The system errors given in (27), (28) and (29) are evaluated for various controllers like HS-
FPID, FPID, PID and compared. Figure 6 shows the comparison of ISE of various controllers and from Figure 6 it is obvious that HS-FPID controller has minimum ISE compared with other controllers. Figures 7 and 8 show the comparison of IAE and ITAE of various controllers. From the comparisons, it is evident that HS-FPID controller shows better performance to track the fuel cell output voltage by minimizing the system errors when compared with FPID, PID and NN Controllers. Hence HS-FPID Controller is considered for the implementation of closed loop speed control in PEMFC-based Electric vehicles.

Here the speed error is calculated by comparing the measured speed with the reference speed $\omega_{\text {error }}=\omega_{\text {ref }}-\omega_{m}$ and the same is provided for the speed controller. The speed controller proceeds with course of action to generate the control voltage as represented in (30) which adjusts the fuel cell output voltage thereby altering the armature voltage . 
$V_{C}=K_{P}\left(\omega_{r e f}-\omega_{m}\right)+K_{I}\left(D_{t}\right)^{-\lambda}\left(\omega_{r e f}-\omega_{m}\right)+$

$K_{D}\left(D_{t}\right)^{\delta}\left(\omega_{r e f}-\omega_{m}\right)$

where $\mathrm{K}_{\mathrm{P}}, \mathrm{K}_{\mathrm{I}}, \mathrm{K}_{\mathrm{D}}, \quad \lambda, \quad \delta$ are the speed controller parameters.

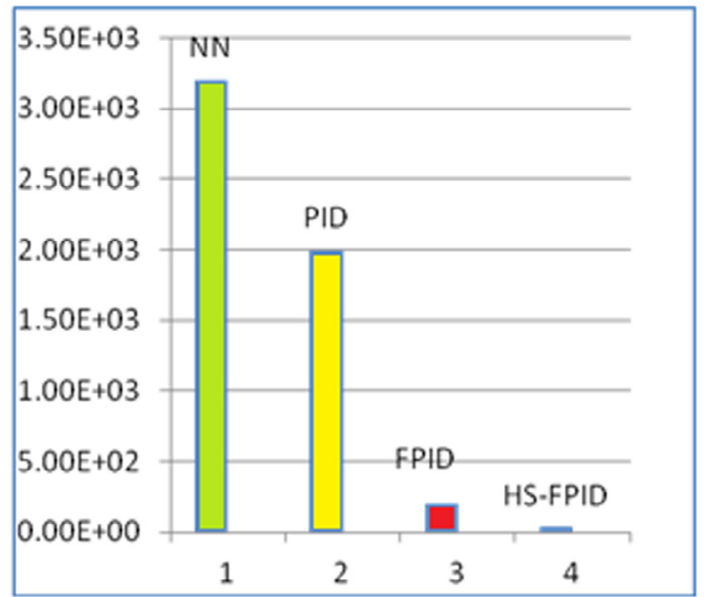

Figure 6. Comparison of ISE

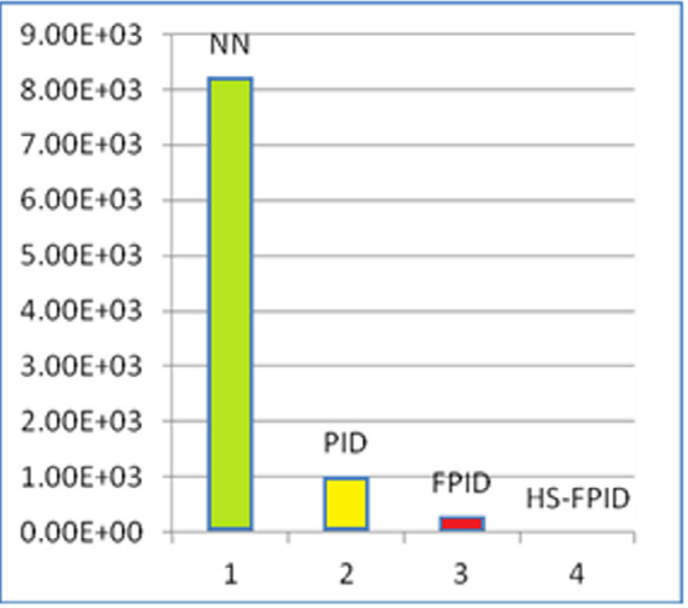

Figure 7. Comparison of IAE

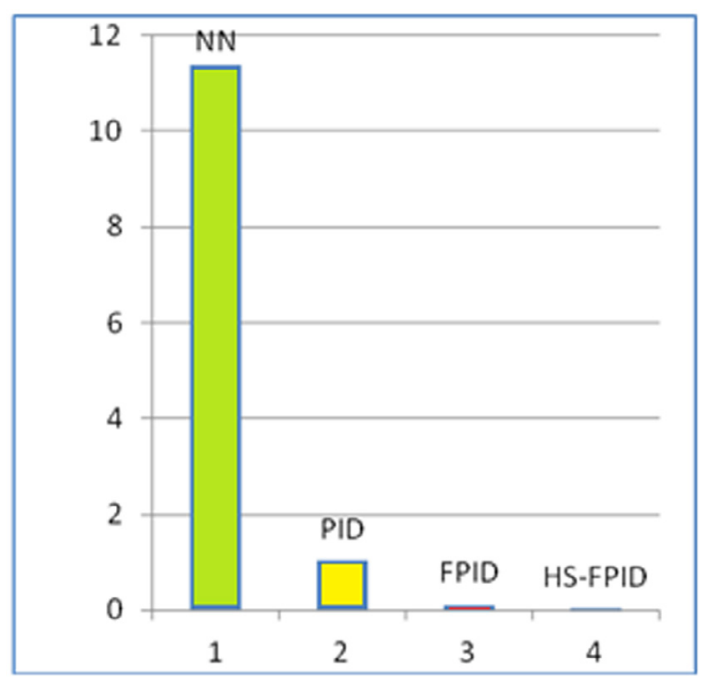

Figure 8. Comparison of ITAE

\section{Simulation Results}

\subsection{Simulation Results under static load conditions}

Here the speed of the DC Motor is regulated by HS optimized Fractional Order PID Controller which generates the required control voltage to alter the fuel cell output thereby controlling the speed of the DC Motor.

The waveforms depicting the variations in controller output, fuel cell output and the output speed are illustrated in Figures 9-11. In order to evaluate the tracking performance of the PEMFCpowered system under static conditions, a reference speed of about $70 \mathrm{rad} / \mathrm{s}$ is provided. The effects on the various variables like the controller output, fuel cell voltage and the motor speed are represented in Figures 9-11.

Based on the results obtained, it can be noticed that the output speed of DC Motor is regulated to the reference value. Therefore it can be positively concluded that the PEMFC-powered system is capable of undertaking optimal tracking of the reference speed. The DC motor is connected across PEMFC and the specifications for the DC motor are given in Table 3 .

Table 3.Specifications for DC Motor

\begin{tabular}{|c|c|c|}
\hline Parameters & Symbol & Value \\
\hline Armature Resistance & $\mathrm{R}_{\mathrm{A}}$ & $0.5 \Omega$ \\
\hline Armature Inductance & $\mathrm{L}_{\mathrm{A}}$ & $0.003 \mathrm{H}$ \\
\hline Torque Constant & $\mathrm{K}_{\mathrm{T}}$ & 1.25 \\
\hline Velocity Constant & $\mathrm{K}_{\mathrm{V}}$ & 0.8 \\
\hline Inertia of the load & $\mathrm{J}$ & $0.0167 \mathrm{Kgm}^{2}$ \\
\hline
\end{tabular}

\subsection{Simulation Results under dynamic load conditions}

In order to evaluate the transient response and tracking performance of the proposed system, a speed reference pattern was implemented sequentially with a varying speed profile as shown in Figure 12. Each command lasts for 0.02 seconds and after each elapsed period, the speed reference 


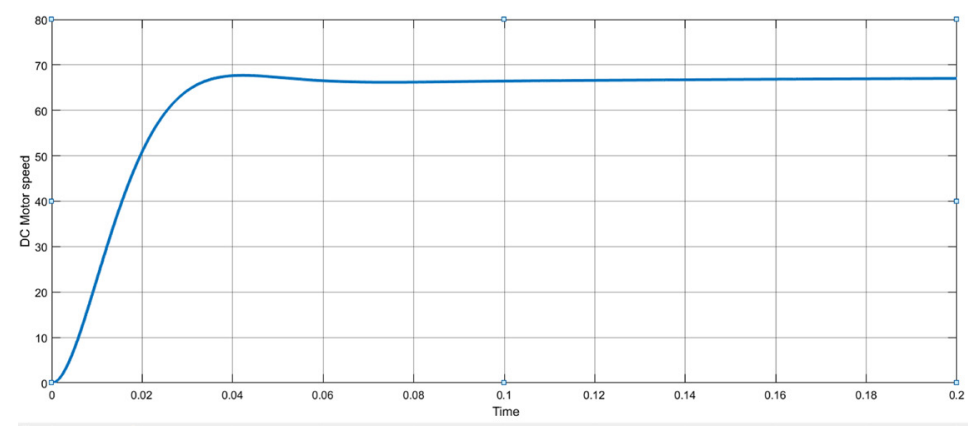

Figure 9. Speed of DC powered by PEMFC

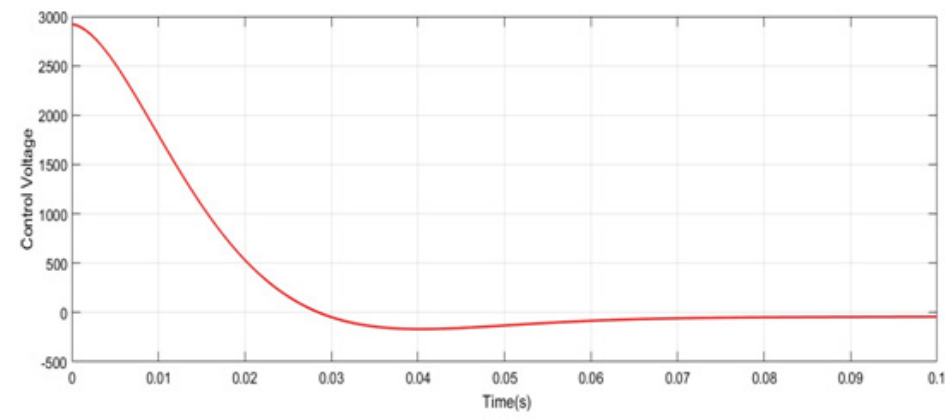

Figure 10. HS-FPID Controller output with respect to speed error

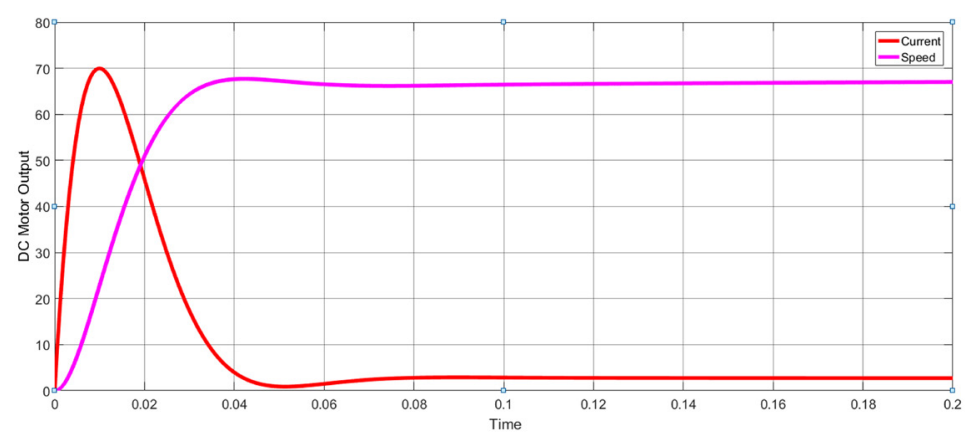

Figure 11. Plot of DC Motor Current Vs Speed

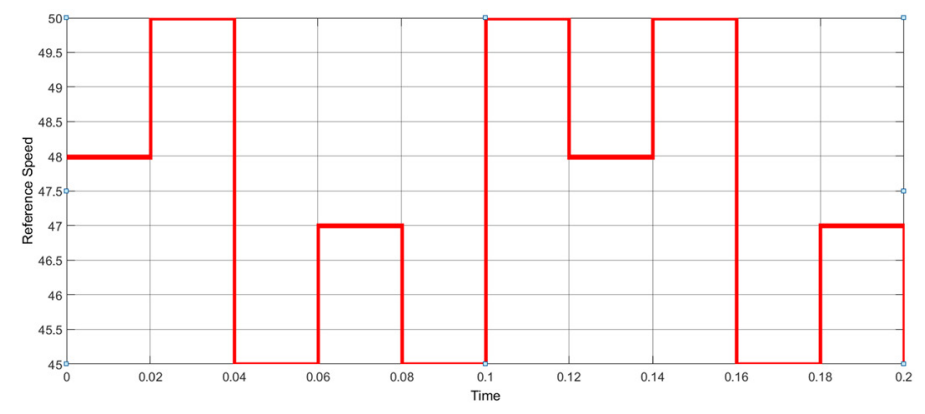

Figure 12. Reference Speed Profile

is changed. Figure 13 illustrates the variation of vehicle speed with the corresponding reference speed The results show that the system is capable of tracking the reference speed very well.

Figure 14 shows the variation in the speed error calculated by comparing the actual speed with reference speed. At the time point of $0.02 \mathrm{~s}$ the speed started to increase and the HS-FPID speed controller responded by a decreased control signal as shown in Figure 15. Consequently, the voltage applied to the vehicle is adjusted to the value required to maintain the predetermined vehicle speed as shown in Figure 16. At the time point of $0.04 \mathrm{~s}$, the speed started to decrease and the HSFPID speed controller responded by an increase in the fuel cell voltage, maintaining constant speed operation. 


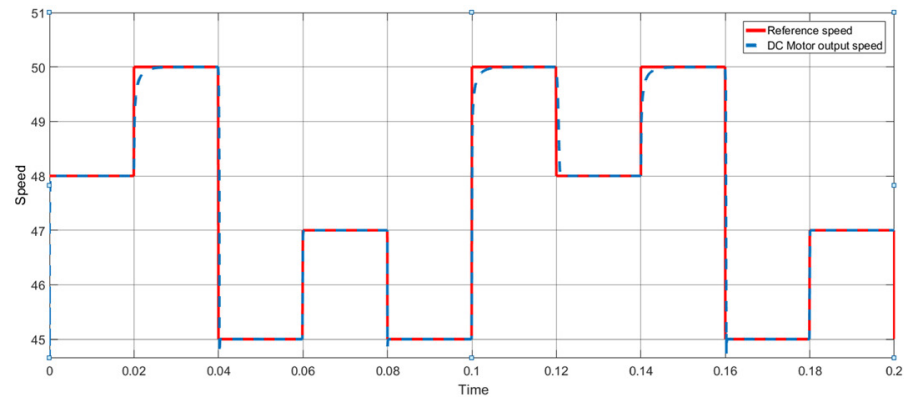

Figure 13. Tracking Performance of PEMFC powered Electric vehicle

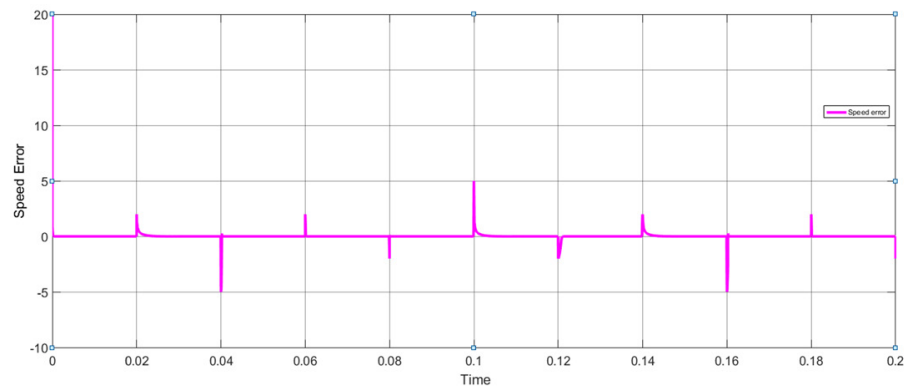

Figure 14. Variation in Speed Error

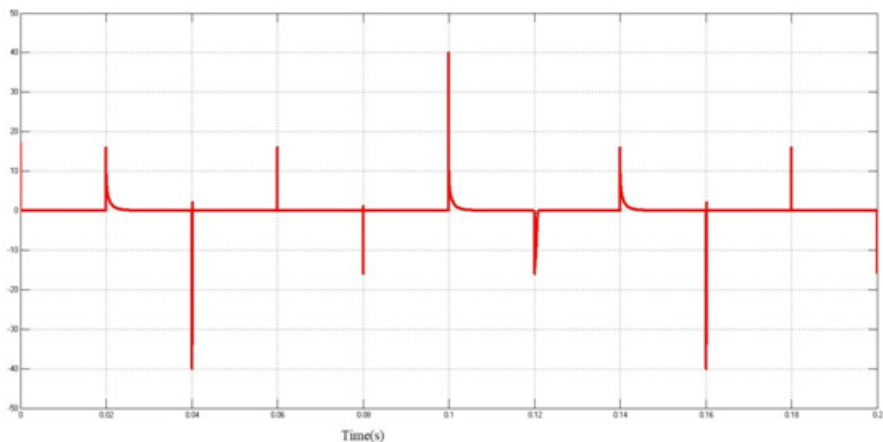

Figure 15. HS-FPID Controller output with respect to speed error

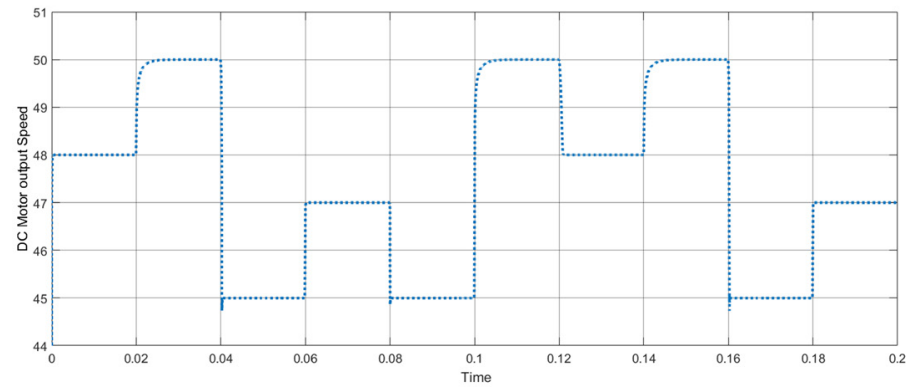

Figure 16. DC Motor Output Speed Variation

In brief, the simulation results indicate that the Hs Optimized FPID Controller (HS-FPID) converges to maximum point with minimal system errors.

\section{Conclusion}

The current paper has presented the implementation of the HS-FPID-based speed control of a PEM fuel cell fed vehicle. Since the Conventional PID Controller is limited to integers, a real time controller that works on fractional values is implemented. The simulation results obtained clearly show that the fractional order PID Controller provided more reactive and steady control thereby maintaining the tracking efficiency. An application of the HS-FPID controller to control the speed of DC Motor is proposed. The HS-FPID controller makes the 
control process simpler, which consumes less computational time and ensures a swift response. The control scheme was implemented under different reference speed levels. The simulation results obtained using MATLAB/Simulink proved

\section{REFERENCES}

1. Ali, E. A. \& Abhudhahir, A. (2011). A Survey of the Relevance of Control Systems for PEM Fuel cells. In IEEE International Conference on Computer, Communication and Electrical Technology (IICCCET) (pp.322-326). IEEE.

2. Al-Othman, A. K., Ahmed, A., AlSharidah, M. E., El-Naggar, K. M. \& Alajmi, N. (2016). Speed Control of Electric Vehicle. In Proceedings of International Conference on Mechatronics, Control and Automation Engineering (pp. 0032-0033).

3. Askarzadeh, A. \& Rezazadeh, A. (2012). An Innovative global Harmony Search Algorithm for parameter identification of a PEM fuel cell model, IEEE Transactions on Industrial Electronics, 59(9), 3473-3480.

4. Barbosa, S. \& Jesus, S. (2013). Comparative Study of Fuzzy integer and Fractional PID Controller. In 39th Annual Conference of the IEEE Industrial Electronics Society (pp. 3392-3397). IEEE.

5. Bilbao, M. N., Del Ser, J., Geem, Z. W., Gil-Lopez, S., Landa-Torres, Manjarres, D. \& Salcedo-Sanz, S. (2014). A Survey on the Applications of the harmony search algorithm, Engineering Applications of Artificial Intelligence, 26(8), 1818-1831.

6. Cao, J. \& Cao, B. (2006). Design of Fractional Order Controller Based on Particle Swarm optimization, International Journal of control, Automation and System, 4(6), 775-781.

7. Chen, Y. Q., Petras, I. \& Xue, D. (2009). Fractional order Control: A Tutorial, American Control Conference AACC (pp.1397-1411).

8. Das, S., Mukhopadhyay, A., Roy, A., Abraham, A. \& Panigrahi, K. (2011). Exploratory power of the Harmony Search Algorithm Analysis and Improvements for Global Numerical Optimization, IEEE Transactions on Systems, Man and Cybernetics, 41(1), 89-95. that the proposed HS-FPID controller is accurate in maintaining the speed at a desired value in spite of dynamic load conditions which is mandatory for Electric vehicles.

9. Fuel Cell Hand Book (2007). 7th edition, EG\&G Technical Services Inc.,3.1-3.23.

10. Kassim, N., Sulaiman, S. I., Othman, Z. \& Musirin, I. (2014). Harmony search Based Optimization of Artificial Neural Network for Predicting AC Power from a photovoltaic system. In IEEE 8th International Power Engineering and Optimization Conference (pp.504-507). IEEE.

11. Maamar., B. \& Rachid., M. (2014). IMC-PID Fractional Order filter Controllers design for integer order systems, ISA Transactions Elsevier, 53, 1620-1628.

12. El Monem, A. A., Azmy, M. \& Mahmoud, S. A. (2014). Dynamic Modeling of Proton Exchange Membrane Fuel Cell for Electric Vehicle Applications, Petroleum and Environmental Technology, 5(2), 1-7.

13. Nandikesan, P., Mohanty, S., Shaneeth, K. P. \& Kamlakaran, M. (2012). Control strategy for PEM Fuel Cell Power Plant. In IEEE I International Conference on Power and Energy (pp.1-3). IEEE.

14. Othman, F., Fakharuzi, M. H. A. M., Hanapi, S., Jenal, N. \& Sainan, K. I. (2017). DC Brushed Electrical Motor Performance Analysis Study of Proton Exchange Membrane Fuel Cell (PEMFC) Automotive Propulsion System, International Journal of Materials, Mechanics and Manufacturing, 5(1), 28-31.

15. Puranik, S. V., Keyhani, A. \& Khorrami, F. (2010). State Space Modelling of Proton Exchange Membrane Fuel cell, IEEE Transactions on Energy Conversion, 25(3), 804-813.

16. Raissi, T. A. \& Banerjee, A. (1997). Current Technology of Fuel Cell Systems. In Energy Conversion Engineering Conference, IECEC-97 (pp. 1953-1957). 
17. Salmasi, F. R. (2007). Control Strategies for Hybrid Electric Vehicles: Evolution, Classification, Comparison, and Future Trends, IEEE Transactions on Vehicular Technology, 56(5), 2393-2404.

18. Singhal, R., Padhee, S. \& Kaur, G. (2012). Design of Fractional Order PID Controller for Speed Control of DC Motor, International Journal of Scientific and Research Publications, 2(6), 1-8.

19. Sopian, K. \& Daud, W. R. W. (2006). Challenges and future developments in proton exchange membrane fuel cells, Renewable Energy, 31, 719-727.

20. Vinu, R. \& Paul, V. (2016). Harmony Search Optimized Fractional Order PID Controller for Voltage Control of Fuel cell, Asian Journal of Research in Social Sciences and Humanities, 6(10), 815-829.
21. Vinu, R. \& Paul, V. (2018). Performance Analysis of Artificial Intelligent Controllers in PEMFC voltage tracking, Cluster Computing, 1-13. doi:10.1007/s10586-018-1992-7

22. Williams, J. G., Liu, G. P., Chai, S. \& Rees, D. (2008). Intelligent Control for improvements in PEM fuel cell flow performance, International Journal of Automation and Computing, 5(2), 145-151.

23. Zhang, Y. \& Li, J. (2011). Fractional Order PID Controller Tuning Based on Genetic Algorithm. In IEEE International Conference on Business Management and Electronic Information (764-767). 